\title{
DAS RAZÕES PARA SER PROFESSOR (DE PORTUGUÊS) HOJE O PROFISSIONAL DE LETRAS: FORMAÇÃO CONSTANTE
}

\begin{abstract}
Resumo: Este artigo procura apontar razões para ser professor (de português) no contexto da sociedade neoliberal brasileira, que construiu ao longo das últimas décadas discursos e práticas de desvalorização da profissão docente. A chave da leitura é (auto-)valorização da profissão com base em exemplos da atuação do professor no âmbito de um projeto de nação que tem na formação docente e na formação de jovens a sua alavanca de sustentação.
\end{abstract}

Palavras-chave: Professor. Atuação. Valorização.

\section{Preâmbulo da conferência ${ }^{1}$}

Gostaria de começar este texto (e esta fala) pelos meus agradecimentos ao convite que me foi formulado, tentando traduzir o sentimento de reconhecimento e de gratidão que me tomou desde quando fui convidada para assumir o honroso(a) lugar/voz na abertura deste Colóquio. Além disso, gostaria também de parabenizar a Tutora do PET LETRAS Profa. Dra. Josilene Mariz pela brilhante ideia de realizar este evento. Quando me foi apresentado o convite, eu tinha praticamente acabado de deixar o lugar de Tutora desse mesmo grupo e me deparei dizendo "UAL que ideia! Eu deveria ter tido uma ideia assim!!" Disse isso a mim mesma e tenho a coragem de dizer aqui, em público, como uma confissão de admiração. Achei a ideia genial porque o convite veio acompanhado da observação de que o Colóquio não pretendia se debruçar sobre a face triste e ingrata da profissão e de suas condições de trabalho. Não que estes aspectos não devam ser tematizados, mas há outros espaços mais politicamente "empoderados" para trazer tais temas à tona com propriedade. Achei a ideia genial também porque olhando o PET agora da condição de ex-tutora e ex-avaliadora do MEC para esse programa vi que a nova tutora logo tratou de dar sua "cara" ao grupo, inovando sobre o bordado, ou seja, propondo novas e desafiadoras atividades a partir daquelas previamente planejadas. E isso é muito bom para o grupo, sobretudo pelas articulações com a PÓS e com outros grupos da graduação como o PIBIC, o PIBID, a Monitoria e a Extensão. Por fim, gostaria de destacar o simbolismo entre a data e a iniciativa. Em vez do tradicional

\footnotetext{
* Professora do Programa de Pós-Graduação em Linguagem e Ensino (PÓS-LE) da Unidade Acadêmica de Letras (UAL) da Universidade Federal de Campina Grande (UFCG). E-mail: deniselinoaraujo@gmail.com.

1 Texto escrito para a conferência de abertura do Colóquio Nacional 15 de Outubro, promovido pelo PET LETRAS e POS LE UFCG. Agradeço a Samelly Xavier a interlocução na disciplina Fundamentos da Prática de Educativa, do curso de Letras UAL -UFCG, fonte das ideias aqui apresentadas.
} 
feriado, um dia de trabalho! Sim, dia de trabalho, de muito trabalho, mas de trabalho reflexivo, em equipe, de discussão e de proposição. Dito isto, vamos ao texto escrito para o Colóquio.

\section{Introdução}

Já não é de hoje que a profissão docente, não importa a área de atuação, está entre uma das mais desvalorizadas do país, seguindo de certo modo, uma tendência internacional que se tornou visível no século $\mathrm{XX}$ e acentuou-se nestas duas primeiras décadas do século $\mathrm{XXI}^{2}$. Numa obra de 2000, o Prof. Júlio Emílio Diniz Pereira (Formação de Professores; pesquisas, representações e poder), demonstrava que as licenciaturas de modo geral são cursos menos prestigiados entre todos os apresentados pelo sistema de ensino superior no Brasil. Para esses cursos, acorrem, de modo geral, alunos mais velhos, alunos trabalhadores, alunos vindos de escolas públicas e alunos que foram aprovados para a segunda ou demais opções nos processos seletivos para ensino superior. Para as licenciaturas, os alunos reais são tidos como "alunos de segunda categoria". Longe de apontar um sentido negativo para esta expressão, quero destacar o contexto a que ela se refere: alunos desmotivados, defasados e com pouco tempo para dedicar à formação inicial seja porque já estão no mercado de trabalho como professores, seja porque se dedicam a outra ocupação laboral na sua condição de cidadão ativo e muitas vezes de arrimo de família.

Recentemente, numa conversa com colegas do ensino superior, discutíamos o impacto da Lei das $\operatorname{Cotas}^{3}$ na UFCG nos próximos 4 anos, período de vigência da lei. Um dos colegas disse que a lei só impactaria apenas 14 cursos e de forma mais específica dois deles. Medicina e Ciências da Computação -, não impactaria as licenciaturas, visto que já estão essencialmente compostas por alunos vindos de escolas públicas, portanto, os $50 \%$ das cotas já estavam "naturalmente", assegurados na prática. Para o meu colega, a lei em vigor era irrelevante para nós porque jovens bem educados, leia-se, que tenham feito sua escolarização na escola privada, que agreguem os propalados valores da pós-modernidade para a juventude, quais sejam protagonismo, capacidade de inovação, boa relação com desafios, línguas estrangeiras e tecnologia não vão procurar os cursos de licenciatura, que são supostamente

\footnotetext{
${ }^{2}$ Para se compreender melhor essa ideia, sugiro consultar o livro Uma professora fora de série, Esmé Rajdi, Ed Sextante, e assistir aos filmes Nenhum a menos, Escritores da Liberdade.

${ }^{3}$ Lei n. $12.711 / 2012$
} 
procurados por aqueles que já veem de uma formação defasada e, portanto, não têm condição de disputar os tais 14 cursos ou aqueles 2 "especiais", preferem o estabelecido ao novo, se ajustam melhor a realidade regional do que a realidade global.

Associando esses dois contextos, qual seja aquele descrito por Pereira (2000) e aquele visibilizado pelo discurso do meu colega, a pergunta óbvia é: quais as razões para ser professor, hoje? Para alguns, talvez seja melhor engrossar o coro dos professores insatisfeitos, não só com a profissão, mas principalmente consigo mesmo, tal como vemos quando vamos às escolas com os estagiários: "mas tão novinho(a), tão bonitinho(a) querendo ser professor?! Seja, não!! Ou o coro dos pais e familiares que esperam o rápido retorno do investimento feito ao longo dos 9 anos da escolarização básica dos filhos: professor, não! Escolha qualquer outro curso. Vai morrer de fome?!" Contrariando esse universo pessimista, tenho razões para ser professora hoje e razões para apresentar aos jovens para serem professores também.

Este texto está, então, organizado em duas partes. Na primeira, apresento essas razões e na segunda tento atender ao tema da conferência proposto por esse colóquio: O profissional de Letras: formação constante. Procedo assim porque descobri ao longo da minha atuação docente a profundidade da resposta de Ariano Suassuna, quando professor de crítica literária na UFPE, no auge da ditadura brasileira. Na ocaisão, por ordem do Estado, os docentes eram transferidos de disciplina, de curso, de universidade, a fim de diminuir a sua liderança sobre os alunos. A Ariano fora designado, por um chefe de Departamento imposto pela Ditadura, a ministar uma disciplina que nunca ministrara e que não era a sua especialidade. $\mathrm{O}$ mesmo havia sido feito com os demais colegas, que evidentemente se revoltaram, se rebelaram e não aceitaram, menos o combativamente pacato Ariano. Até que um colega revoltou-se com a sua tranquilidade e em plena assembleia departamental exortou-o a se manifestar, propondo o repto: “E você Ariano, não vai dizer nada, não?! Vai baixar a cabeça pros milicos?" Ele respondeu impassível: "Eu não, eu só sei ensinar uma coisa só [crítica literária], tanto faz o nome que derem! (sic!)" Tenho descoberto com a vida que, assim como Ariano, cujas comparações não são cabíveis comigo, parece que eu, modestamente, vale aqui dizer, colocando-me para a crítica de vocês, também só sei ensinar uma única matéria, que é formação docente, motivo pelo qual este texto resulta da minha atuação nos últimos anos nas disciplinas Prática de Ensino de Língua e de Literatura Brasileira (conhecida como Prática II) e mais recentemente Fundamentos da Prática Educativa, graduação, e Seminários de Pesquisa, no POS LE. Portanto, meus agradecimentos a todos/as os/as alunos/as com quem travei interlocução nas várias versões dessas disciplinas. 


\section{Das razões para (não) ser professor (de português) hoje}

Na minha compreensão, são de duas ordens as razões para ser professor/a hoje. Razões de ordem laboral que não nos fazem diferentes dos demais trabalhadores e razões de ordem emocional, vocacional ou de habilidade.

Uma primeira razão para não ser professor hoje diz respeito ao salário. Vou começar exatamente pelo salário porque é o ponto universalmente apontado como menos motivador. As comparações geralmente são feitas com médicos, advogados e programadores de computador ou desenvolvedores de software. Essas três profissões são tidas como glamorosas, como aquelas que pagam muito bem e como investimentos de médio prazo que rendem muito alto ao longo da vida. Comparados professores, médicos, advogados e programadores, realmente exibem disparidades evidentes, porém, cabe lembrar que médico bem remunerado não é exatamente uma regra na profissão, que já se encontra tão sucateada quanto a nossa, sem falar que a jornada de trabalho é mais intensa do que a nossa. Advogados, em geral, não ganham bem na primeira causa que defendem, apesar da aparência pelas roupas que vestem. Desenvolvedores vivem o novo Eldorado do Vale do Silício em Star Ups a procura de investidores que coloquem milhões de dólares em seus aplicativos.

Professor ganha muito mal no Brasil; na Paraíba e em Campina Grande isso não é diferente. A propaganda eleitoral de um dos candidatos a prefeito este ano afirmava que, se eleito, pagaria o piso salarial a professores (sic!), ou seja, nem o piso é pago aqui. Essa razão engrossaria os argumentos dos que não veem razão para se diplomar nas licenciaturas. Todavia, enfermeiros, policiais, jornalistas, bibliotecários, assistentes sociais, psicólogos, administradores, etc também não ganham bem. $\mathrm{O}$ mito do jovem adulto com menos de trinta anos que já ganhou um milhão de dólares é uma invenção da sociedade neoliberal e consumista para extrair toda a força de trabalho dos jovens que doam os mais produtivos e saudáveis anos de suas vidas a causas muitas vezes sem solução. Há jovens que chegaram a essa cifra, porém a quantidade deles não é expressiva num mundo em que cada vez mais busca uma colocação no mercado de trabalho.

Esse mesmo discurso, porém, não diz aos jovens que de todas profissões acima citadas a de professor é a que tem mais chances de empregabilidade, porque numa nação de 190 milhões de pessoas como a nossa precisa evidentemente, em números absolutos, muito mais de professores do que de médicos, advogados ou engenheiros, há demanda para isto. A oferta é que já começa a escassear visto que as condições de trabalho foram historicamente 
deterioradas e mão de obra qualificada não se submete a condições ruins num mercado com oportunidades variadas. Em conversa recente com uma empresária do setor, obtive a informação de que os salários não podem mais ser baixos simplesmente porque não há professor no mercado. Também em uma conversa recente com uma professora da educação infantil de uma capital do sudeste, ela me disse que, por uma jornada de 20 horas semanais, a escola em que ela trabalhava, daquelas que figuram em primeiro lugar todos os rankings governamentais, o salário liquido é de 4 salários mínimos ${ }^{4}$ e não há professores suficientes na cidade. Outro dado que completa esse quadro e faz parte da nossa realidade diz respeito à migração de professores de Campina e da Paraíba para cidades de Pernambuco onde o salário é melhor do que os que são pagos aqui, mas baixos para a história de lutas dos professores daquele estado, que não os aceitam. Soma-se a isso, o recente investimento do MEC no programa PIBID, com o objetivo de torná-lo tão atraente dentro e fora da Universidade quanto o PIBIC. Pelo que podemos observar, há uma mudança em curso, lenta, mas há.

Outra razão que se apresenta aos jovens para não serem professor(es)/as diz respeito às condições de trabalho. Novamente o discurso do desestímulo diz que as nossas condições de trabalho são ruins, aliás, diz que são péssimas. E de fato são! Porém, da mesma forma, médicos trabalham em péssimas condições. Pergunte a um médico do SUS, do PSF, o que ele tem a dizer sobre o sistema. Certamente, será unanimidade o fato de que a filosofia do sistema é brilhante, mas as condições objetivas são péssimas, falta tudo. Advogados, policiais, enfermeiros também trabalham em condições ruins etc. Engenheiros nem sempre, mas isto depende da área, da empresa, do ramo de negócio, etc.

Ao dizer isto, não quero fazer entender que se está ruim para todo mundo, melhor é se conformar. Não! Quero desmitificar, principalmente, para os jovens ingressantes que ainda estejam em dúvida se continuam nas licenciaturas, e em Letras em especial, é que não há tanto glamour em outras profissões como faz acreditar o discurso de desvalorização da nossa condição de trabalhadores. Portanto, a meu ver não são as condições de trabalho que me fazem dizer para alguém não ser professor/a.

Outra razão para ser não professor diz respeito aos perigos da profissão. De fato, é perigoso ser professor hoje porque os índices de criminalidade nas escolas dos diferentes níveis de escolaridade tomam as páginas policiais, como fez notar a dissertação de Romeu (2010) defendida no programa POS LE. Da mesma forma, médicos, advogados, jornalistas, enfermeiros, engenheiros enfrentam situações de violência e de estresse patologicamente

\footnotetext{
${ }^{4}$ Valor de referência $\mathrm{R} \$ 622,00$
} 
diagnosticado, como a Síndrome de Burnout, porque a violência é, infelizmente, condição constitutiva de uma sociedade que se baseia numa concepção egoíca de favorecimento, que não investe na educação para a tolerância e para a convivência com a diferença. Além disso, se baseia na divisão entre ricos e pobres, brancos e negros, homens e mulheres, na produção de lucro a todo custo. Uma sociedade baseada nesses valores está doente e vai dar o combustível para que loucos como o atirador de Realengo ${ }^{5}$ adentrem uma escola e se sintam no direito de desferir contra alunos e professores. Ou para que um detento fugitivo entre num posto de saúde e faça de escudo um paciente que estava na fila de espera e defira contra ele dois tiros para barbarizar a situação por si só bárbara ${ }^{6}$ !

Colocadas essas condições ou postas as regras dos "jogos voraze ${ }^{7}$ s da juventude": jovens universitários, recém-egressos de seus cursos vão entrar no mercado de trabalho e vão lutar com dificuldades semelhantes: baixos salários, condições de trabalho ruins, perigo, violência, jornadas exaustivas, solicitação de investimento na formação continuada, etc. Imaginar que alguém que saia da universidade e tenha imediatamente bons salários, jornada de trabalho condizente com condições de dignidade, pacotes de benefícios, etc, não é ainda uma realidade num país que luta para erradicar a pobreza, como propala o slogan do atual governo - País rico é país sem pobreza -, e que cobra altos impostos de todos - empregadores e empregados, e os distribui muito mal. Num mundo regido pela ótica neoliberal, trabalhadores são trabalhadores, ou seja, são massa de produção! Ter de saída essas condições superadas, só para quem as herda.

Portanto, as condições objetivas de trabalho em nossa profissão de fato são ruins, mas não são uma exceção. Trabalhadores do mundo inteiro estão às voltas com suas condições de trabalho. No nosso caso, a situação torna-se dramática, porque o discurso do desestímulo que serve a essa ordem de exploração tratou não apenas de se divulgar como de se fazer aceito. Se para a docência, ao longo dos últimos anos, tivessem sido atraída uma forte concorrência, dificilmente esse sistema teria se instituído.

Colocadas a parte essas condições de ordem laboral, que apesar de difíceis não me desestimula, passo às razões de ordem emocional. Diz um ditado popular chinês: trabalhe no que goste e você não terá um só dia de trabalho. Eu acredito nisto.

\footnotetext{
${ }^{5}$ Ver relato em http://g1.globo.com/Tragedia-em-Realengo/

6 Ver relato em http://globotv.globo.com/rede-globo/globo-noticia/v/morre-mulher-que-virou-refem-debandidos-em-posto-de-saude-no-suburbio-do-rio/2123793/

${ }^{7}$ Alusão ao livro Jogos Vorazes de Suzanne Collins
} 
Para quem gosta ou tem habilidade de lidar com pessoas de diferentes personalidades, coordenando e concatenando suas ideias, gosta de falar em público, de trabalho em grupo, tem espírito de liderança, se sente desafiado pela criatividade e pela inovação, e sente que pode dar uma contribuição a um projeto de nação, a docência é a sua área.

Para o exercício da nossa profissão, é necessário além do investimento pessoal na qualificação, habilidade para lidar com pessoas diferentes, pois os alunos não são semelhantes, sequer iguais, ainda que tenham a mesma idade, cursem a mesma série, morem no mesmo bairro, frequentem os mesmos lugares, etc.

Exige ainda a habilidade de falar em público e para isso não basta apenas ser desinibido, faz-se necessário saber didatizar (Rafael, 2000), a fim de produzir o entendimento por parte daquele que desconhece o assunto.

Se o candidato à docência sente-se a vontade em grupo, certamente terá menos tendência a realizar seu trabalho de modo solitário como exige a ordem vigente, tal como descrevem Tardif e Lessard (2009). O isolamento é uma técnica antiga de opressão, que só é vencida quando os isolados desenvolvem esquemas de subversão. Em nossa profissão, Nóvoa (1999) definiu isto como descobrir "novos sentidos para a ideia de coletivo profissional". Nas palavras do autor:

É preciso inscrever rotinas de funcionamento, modos de decisão e práticas pedagógicas que apelem à co-responsabilização e à partilha entre colegas. É fundamental encontrar espaços de debate, de planificação e de análise, que acentuem a troca e a colaboração entre os professores. (1999, p.16).

Ademais, liderança é necessária não apenas na área de gerência ou de engenharia. Gauthier (1998) fala claramente em gestão da classe e do conteúdo, apresentado duas funções docentes que exigem "razão e sensibilidade", ou seja, que exigem formação técnica, mas também intuição, cálculo sobre perdas e ganhos, essencial e assessório, visão de futuro, avaliação do presente. Não estou falando sobre bolsas de valores, mas sobre as decisões que como professores todos tomamos a cada aula. Para esses autores, os professores tomam decisões relativas à gerência de classes, portanto, gerência de pessoas, e à gerência de conteúdos, portanto, gerência de transposição didática. Essas gerências exigem, por sua vez, criatividade e inovação porque dizem respeito ao manejo de pessoas em direção ao conhecimento. E ambos mudam, por isso, certos processos logo ficam obsoletos exigindo novos arranjos. 
Por fim, uma razão fundamental para ser professor é a (utópica) ideia de contribuir para um projeto de nação. E aqui me dou o direto de contar uma história pessoal. Há algum tempo, estava em Brasília, participando de uma das várias reuniões de que participei e já não lembro mais se o tema havia sido o PET ou o ENEM. Fato é que fiquei na capital federal para retornar num sábado, após a reunião. Ao acordar naquele dia, abri a cortina da janela do quarto do $14^{\circ}$ andar de um dos hotéis da cidade que dá de frente para o planalto central. A forte luz do sol às 7 horas da manhã iluminou o quarto e a mim, por dentro. Naquele momento me perguntei o que fazia ali, para que servia a minha vida, se eram válidos os meus esforços na profissão que me exigem constantemente menos interação familiar e com amigos do que eu gostaria. Num lance rápido, a minha mente ordenou fatos diferente. Lembrei-me da biografia de pessoas anônimas e de vultos que lutaram por essa nação. Lembrei-me também de que na Grécia antiga havia muita exclusão, mas havia um projeto que era unanimidade: um projeto para os jovens, que eram encaminhados para as escolas para serem os melhores: melhores atletas, melhores políticos, filósofos, professores, melhores em tudo. Os jovens, pelo menos os que iam para as escolas, não trabalhavam até que finalizassem seus estudos. Minha mente excitada naquele momento, alinhada à minha emoção otimista, elaborou uma resposta de profundidade: vale a pena ser professor para participar da construção um projeto de nação em que o jovem de fato seja protagonista, para isso é necessário se colocar no ponto de interlocução e de contraposição à proposta precoce do primeiro emprego, programa menor aprendiz e assemelhados.

Conclui que todos nós professores de Língua e de Literatura podemos participar ativa e reflexivamente desse projeto de nação porque lidamos com a linguagem. É em nossas aulas que trabalhamos textos como a Canção Amiga de Drummond, para despertar a alma dos nossos alunos. Mas é também nessas aulas, que podemos analisar a construção de uma afirmativa como a de Ariano citada antes: Eu não, eu só sei ensinar uma coisa só, e entender a dupla presença do advérbio só na estruturação da declaração afirmativa que constrói um enunciado único, no âmbito de uma enunciação polissêmica e de verdadeira contraposição à ordem estabelecida no contexto do qual foi retirada, que, à luz da afirmativa de Nóvoa (1999), já citada, é uma forma de co-responsabilização na profissão.

Somente nas aulas de língua e de literatura é possível desvelar com propriedade o discurso por traz da declaração de um candidato que diz que, se eleito, pagará o piso aos professores. Por quê? Com quem ele dialoga? Por que outros profissionais da mesma rede psicólogos, assistentes sociais, merendeiras, etc - não recebem esse "destaque". O que ele diz é bom ou é ruim? E para quem? De que ponto de vista? Quem são seus reais interlocutores? 
Em suma, a razão maior para ser professora e para estimular outros/as a serem professores/as é demonstrar-lhes que quem ensina lida com a mente e a emoção dos jovens (crianças, adultos). Se quem lê este texto, sente que pode influenciar mente e emoções, a pergunta é por que não ser professor?!

\section{O profissional de Letras: formação constante}

Como disse anteriormente, o professor de língua e de literatura tem condições objetivas de tematizar as contradições do mundo pós moderno, assim como de trabalhar com a memória e a história porque a Linguagem é nosso objeto de trabalho/investigação. Nesse sentido, ensinar essas matérias/disciplinas ou os conteúdos a elas associados exige uma formação constante dado à sua natureza mutante, mas também conservadora. A língua não muda porque quer mudar, muda porque é possível/necessário mudar, mas muda dentro de certas condições que lidam o tempo todo com duas forças uma centrípeta e outra centrífuga: mudança e conservação. O mesmo se dá com a literatura: os clássicos e os contemporâneos tematizando a condição humana e influenciando seu modo de ser. Logo, esse objeto exige formação constante uma vez que se estrutura sobre um terreno movediço.

Além dessa natureza movediça, muito mais do que o mercado, mas os alunos - pela sua condição de aprendizes - exigem atualização de nossa parte. São recorrentes os casos e causos de professores atualizados pelos seus alunos em relação aos quais não despertam nenhuma paixão, nenhum entusiasmo. Recentemente, estive com muitos jovens universitários que apontaram performances detestáveis de seus professores, assim elencadas: seminários das matérias que os professores não sabem; desconhecimento das (re)leituras de conceitos clássicos; desvinculação da matéria com a vida prática.

A formação constante tornou-se ainda mais necessária com a popularização da internet. $\mathrm{E}$ ao dizer isto não estou me referindo à temida e odiada educação à distância, mas às novas formas de ensinar e de aprender com a internet. A recém criada Khan Academy ou o polular Livemoch ${ }^{8}$, antes de nos tirarem do centro da sala de aula como gestores da classe e do conteúdo (cf. Gauthier, 1998), nos colocaram de volta no centro porque os alunos podem acessar as aulas expositivas ou aprender com falantes nativos, mas só professores são capazes de elucidar dúvidas, ampliar fronteiras, indicar fontes, interrelacionar saberes.

\footnotetext{
${ }^{8}$ Ver www.khanacademy.org/ e livemocha.com/
} 
Os desafios dessa formação oscilam entre o que é possível realizar sozinho e o que pode ser buscado em parceria com o estado/empregador. Para esse, como para todos os demais aqui apontados, creio que os caminhos apontados por Nóvoa (1999:18) são elucidativos de que há saída para nossa profissão. O autor advoga que descubramos "uma identidade coletiva que [nos]permita descobrir [nosso] papel na formação das crianças e dos jovens". Além disso, defende que, quanto à formação, integremos reflexivamente nossa experiência como aluno, aluno-professor, estagiário, professor principiante, titular e aposentado. Indica que a dimensão educativa da profissão expande-se para além da dimensão técnica do lecionar. Sublinha que as decisões do professor se baseiam nas situações singulares, e com base em suas convicções pessoais e nas suas discussões com colegas. Por fim, esclarece que o associativismo docente avança para além do sentido corporativo para incorporar os interesses científicos e pedagógicos da profissão.

Em outras palavras, temos nesses 4 itens uma agenda para o século em curso. As demandas da profissão não poderão esperar que todos os problemas sejam resolvidos para que os professores entrem em sala de aula, mas será necessário consertar o trem enquanto se está andando nele. O que nos dá uma assustadora ideia de perigo, por isso, muita gente prefere pensar como na música Tocando em Frente ${ }^{\underline{11}}$, de Almir Sater e Renato Teixeira: Ando devagar porque já tive pressa.

\section{4. À guisa de conclusão 9}

O discurso do desestímulo à formação docente certamente apontará como bobos os argumentos aqui apresentados a favor da opção de ser professor. Também poderá fazer com que professores da educação básica acreditem que o que aqui foi dito resulta do fato de eu ser docente do ensino superior, esquecendo-se que também foi professora da escola básica e de jovens e adultos.

Todavia, os argumentos apresentados são os que ao longo da minha atuação docente fui construindo, encontrando e reafirmando a escolha que fiz anos atrás: vestibular para Letras, depois, na graduação, habilitação em Português, um pouco mais adiante formação de professores/as de português.

\footnotetext{
${ }^{9}$ Ao concluir a revisão deste artigo, deparei com a seguinte notícia que corrobora tudo o disse que aqui: http://www.unesco.org/new/en/media-services/single-view/news/three_years_to_address_the_teacher_challenge/
} 
Por fim, o exercício da docência me fez encontrar a melhor metáfora para a minha/a nossa atuação. Como dizem Tardiff e Lessard (2009, p.63), O mestre é o centro da atividade na classe. Ele é o sol do sistema pedagógico... esses autores fazem uma pertinente crítica a essa metáfora dizendo que, não raro, assumimos solitariamente toda a carga de um sistema de transferência de responsabilidade, seja do estado para as instituições escolares, seja da sociedade para os professores como trabalhadores, seja dos pais para os educadores. Não obstante, o sentido positivo dessa metáfora é o mais inspirador para mim, é o que me faz respirar fundo e dizer que vale a pena ser professor. Qualquer semelhança com aquele sol de Brasília, que me fez pensar em ser um ponto de articulação num projeto de Nação não é ser mera coincidência!

\section{Referências}

NÓVOA, António. Os Professores na Virada do Milênio: do excesso dos discursos à pobreza das práticas. Revista Educação e. Pesquisa. vol.25 no.1 São Paulo Jan./June 1999.

PEREIRA, Júlio E. D. Formação de professores: pesquisas, representações e poder. Belo Horizonte: Autêntica. 2006.

ROMEU, Silvanya S. de Lima. As imagens dos sujeitos de ensino pelas lentes da mídia como jogos de verdade: uma construção da realidade. Dissertação de Mestrado, Programa de Pósgraduação em Linguagem e Ensino, UFCG, 2010.

TARDIF, Maurice \& Lessard, Claude. O trabalho docente: elementos para uma teoria da docência como profissão nas interações humanas. Tradução João Batista Kreuch. Petrópolis: Vozes, 2009. 